\title{
The roles of teacher-student relationship quality and self-concept of ability in adolescents' achievement emotions: temperament as a moderator
}

\author{
Anna-Leena Clem ${ }^{1}$ - Kathleen M. Rudasill ${ }^{2}$ Riikka Hirvonen ${ }^{1} \cdot$ Kaisa Aunola $^{1}$ • \\ Noona Kiuru ${ }^{1}$
}

Received: 29 June 2019 /Revised: 6 December 2019 / Accepted: 21 February 2020 /

Published online: 14 March 2020

(C) The Author(s) 2020

\begin{abstract}
This study examined to what extent teacher-student conflict and closeness, on the one hand, and students' self-concepts of ability in literacy and mathematics, on the other, are related to students' achievement emotions (enjoyment, anxiety and boredom) in mathematics and literacy among Finnish early adolescents $(N=854)$. We also investigated the extent to which these associations are moderated by student temperament (surgency/extraversion, negative affectivity and effortful control). The results showed, after accounting for relevant covariates, that in both school subjects, teacher-student conflict was negatively related to enjoyment and positively to anxiety and boredom, whereas teacher-student closeness was positively related to enjoyment and negatively to boredom. Self-concepts of ability in both school subjects were positively related to enjoyment and negatively to anxiety, whereas the self-concept of ability was only negatively related to boredom in mathematics. Student temperament also moderated some of the associations in the literacy domain. Lower levels of conflict in the teacher-student relationship were related to higher levels of enjoyment in literacy, particularly among students who had lower levels of surgency/extraversion. Also, a closer relationship with the teacher or a lower self-concept of ability in literacy was related to higher levels of anxiety, particularly among students who had low effortful control. In the mathematics domain, the associations between the self-concept of ability and achievement emotions were somewhat stronger than in literacy, and the domain-specific associations were not dependent on student temperament.
\end{abstract}

Keywords Adolescence · Achievement emotions · Self-concept of ability · Teacher-student relationship · Temperament

This investigation was conducted as part of an ongoing longitudinal Finnish study called the STAIRWAY Study (Ahonen and Kiuru 2013).

Noona Kiuru

noona.h.kiuru@jyu.fi

1 Department of Psychology, University of Jyväskylä, P.O. Box 35, 40014 Jyväskylä, Finland

2 Department of Foundations of Education, Virginia Commonwealth University, Richmond, VA, USA 


\section{Introduction}

Students experience a variety of emotions related to learning activities (Raccanello et al. 2013). In previous literature, positive emotions (e.g. enjoyment) have been found to be beneficial for motivation and facilitative of the use of flexible learning strategies, thus enhancing achievement (e.g. Pekrun et al. 2002), whereas negative emotions (e.g. boredom) have been found to have adverse effects on motivation, cognitive resources and learning strategies, and thereby have a negative impact on performance (e.g. Goetz and Hall 2014). According to Pekrun's (2006) control-value theory of achievement emotions, antecedents of achievement emotions include characteristics of students, such as the self-concept of ability, on the one hand, and instructional and social factors, on the other. In previous empirical research (for an overview, see Pekrun and Perry 2014), the role of students' self-concept of ability in achievement emotions has been well established, whereas the role of the quality of teacher-student relationships is less studied. It has also been suggested that student temperament, that is, individual differences in responding to external and internal stimuli and in regulating these reactions (Rothbart and Bates 2006), might impact adolescents' developmental plasticity and susceptibility to environmental influence (Belsky and Pluess 2009). However, it is not known what role adolescent temperament plays in the associations of the self-concept of ability and the teacher-student relationship with achievement emotions. Consequently, this study aimed to investigate the roles of the self-concept of ability and the teacher-student relationship in the evolvement of early adolescents' achievement emotions and to discover whether these associations differ depending on adolescent temperament.

\section{Self-concept of ability as an antecedent of achievement emotions}

Achievement emotions refer to emotions that relate to achievement outcomes or to emotions that occur during achievement-related activities (Pekrun and Perry 2014). The present study examined frequently experienced achievement emotions (Goetz and Hall 2014), namely, enjoyment, boredom and anxiety, among early adolescents. Because previous research has shown that achievement emotions are domain-specific (e.g. Goetz et al. 2007; Raccanello et al. 2013), in the present study, achievement emotions were assessed separately in two central academic subjects, namely, mathematics and Finnish language.

According to the control-value theory of achievement emotions (Pekrun and Perry 2014), students' control and value appraisals are central to the emergence of achievement emotions. The self-concept of ability forms a basis for experiences of subjective control over achievement activities and outcomes. In previous research, self-concepts of ability in different subject domains have been found to be positively related to enjoyment and negatively to boredom and anxiety (Bieg et al. 2013; Goetz et al. 2006, 2010). However, the majority of the studies investigating the relations between the self-concept of ability and achievement emotions have been conducted on older students, and less is known about these associations in primary school students (see also Pekrun and Perry 2014). Consequently, the first aim of the present study is to investigate the domain-specific relations of maths and literacy self-concepts of ability and achievement emotions in sixth-grade adolescents.

\section{Teacher-student relationship quality and achievement emotions}

According to the control-value theory of achievement emotions, not only are individual characteristics potential sources of emotions but instructional and social antecedents are also 
important antecedents of achievement emotions (Pekrun and Perry 2014). The present study focuses on teacher-student relationship quality, applying an attachment-based teacher-student relationship model (see also Pianta 2001; Verschueren 2015). In this model, closeness and conflict are considered as key dimensions of the teacher-student relationship. Closeness is characterised by high levels of affection and open communication between the teacher and the student, whereas conflict refers to perceived negativity within the teacher-student relationship (Jerome et al. 2009; Pianta 2001).

Teacher-student relationships are developmentally significant for students' socioemotional adjustment and achievement in school (e.g. Bergin and Bergin 2009; Hamre and Pianta 2001; Pakarinen et al. 2018). There are several theoretical reasons as to why teacher-student relationship quality can be assumed to also be related to adolescents' achievement emotions. For example, close and supportive teacher-student relationships can boost adolescents' sense of social relatedness and belonging within the classroom, which, in turn, may promote positive and hinder negative emotions towards learning (Meyer 2014; Sakiz et al. 2012; Skinner et al. 2014). Although teacher-student relationship quality has been found to be important in terms of academic outcomes, such as higher school engagement and academic performance (for a meta-analysis, see Roorda et al. 2011), less is known about the role of the teacher-student relationship quality in the arousal of early adolescents' subject-specific achievement emotions. Previous empirical studies have suggested that high teacher support tends to be related with lower negative and higher positive achievement emotions (for a meta-analysis, see Lei et al. 2018). However, less is known about the role that teacher-student relationships have on single achievement emotions, such as enjoyment, boredom and anxiety. There is nevertheless some evidence to suggest that high-quality teaching is related to more enjoyment and less boredom and anxiety in mathematics and Latin among students in grades 5-10 (Frenzel et al. 2007; Goetz et al. 2006). Similarly, there is some evidence among students in grades 8-11 that suggests that a teacher's supportive presentation style is related to higher learning enjoyment and decreased boredom but not related to anxiety, whereas a teacher's excessive lesson demands are related to higher anxiety and boredom and lesser enjoyment (Goetz et al. 2013). Teacher punishment behaviour, in turn, has been found to be related to higher levels of anxiety and boredom (Frenzel et al. 2007). However, less is known thus far about how early adolescent-perceived closeness and conflict in the teacher-student relationship are related to achievement emotions. Therefore, the second aim of the present study is to find out to what extent the closeness and conflict of teacher-student relationships are related to adolescents' boredom, enjoyment and anxiety with regard to literacy and mathematics.

\section{Temperament as a moderator}

According to the diatheses stress and differential susceptibility models (Belsky and Pluess 2009), individuals with different temperaments vary in their developmental plasticity and susceptibility to environmental influence. Temperament can be defined as early occurring individual differences in reactivity towards environmental and internal stimuli and in selfregulation modulating this reactivity (Rothbart and Bates 2006). Temperament develops via a complex interplay among genes and biological and environmental factors (Shiner et al. 2012), and, thus, it is influenced by experience and maturation (Rothbart and Derryberry 1981). In the present study, we applied Rothbart's temperament model, which has consistently identified three broad dimensions of temperament (Rothbart 2011; Rothbart and Bates 2006; Rothbart and Hwang 2005). Effortful control refers to the ability to control behaviour and regulate 
emotions, including attentional, inhibitory and activation control. Negative affectivity refers to individual differences in proneness to distress and negative emotions and rate of recovery. Surgency/extraversion relates to individual differences in approach behaviour and positive affect.

The goodness-of-fit model (Thomas and Chess 1977) posits that goodness of fit (i.e. adaptive outcome) will result if the child's or adolescent's temperament fits well with the demands and expectations of the environment. However, the most typical environment that has been studied in relation to temperament characteristics is the parent-child relationship, along with parenting behaviours (e.g. Rothbart and Bates 2006). As far as we know, no previous studies have investigated whether student temperament moderates the associations between the teacher-student relationship and achievement emotions. However, there are a few studies on other student outcomes. For example, previous research has suggested that children and adolescents with low levels of effortful control may particularly benefit from positive relationships with teachers as demonstrated by decreased problem behaviours (Wang et al. 2013) and increased academic achievement (Rudasill et al. 2010). There is also some evidence suggesting that children with high effortful control are less influenced by a negative teaching style in terms of general anxiety symptoms compared to children with weaker effortful control (LaBillois and Lagacé-Séguin 2009).

Similarly, as temperament may make some adolescents more susceptible to teacher effects, it may play a role in how self-concept affects emotions. Temperament can influence how students interpret their experiences (Lonigan et al. 2004; Shiner and Caspi 2012). For example, previous research has shown that effortful control plays a role in modulating the affective consequences of threat-relevant stimuli (Lonigan et al. 2004). Thus, higher effortful control may provide protection from the detrimental effects of a low selfconcept on achievement emotions by allowing the shifting of attention from threatening stimuli and internal feelings of inadequate ability to more positive information that enables efficient coping, whereas weak effortful control may make students susceptible to focusing on their internal distress, thus exacerbating the effects of a low self-concept on achievement emotions (see also Derryberry and Rothbart 1997; Rothbart and Jones 1998). However, to our knowledge, research on the interactions of the self-concept of ability and temperament on achievement emotions is lacking. Therefore, the present study also investigated the extent to which adolescent temperament moderates the associations between teacherstudent relationship quality and self-concepts of ability with achievement emotions in literacy and mathematics.

\section{Research questions and hypotheses}

The aim of the present study was to examine the role of teacher-student conflict and closeness and students' self-concepts of ability in students' achievement emotions in mathematics and literacy. Student temperament was considered as a possible moderator in these associations. The following research questions were investigated:

(1) a) To what extent are adolescents' self-concepts of ability in literacy and mathematics associated with adolescents' achievement emotions (i.e. enjoyment, anxiety and boredom) towards literacy and mathematics? and (b) Do these associations differ depending on adolescent temperament? 
H1a: Based on earlier research (e.g. Goetz et al. 2010), we expected to find positive relationships between self-concepts of ability and learning enjoyment and negative relationships between self-concepts of ability and learning anxiety and boredom.

H1b: Due to the scarce previous research regarding temperament and achievement emotions, we did not set specific hypotheses regarding the moderating role of temperament.

(2) a) To what extent are closeness and conflict in the teacher-student relationship associated with adolescents' achievement emotions (i.e. enjoyment, anxiety and boredom) towards literacy and mathematics? and b) Do these associations differ depending on adolescent temperament?

H2a: We expected that closeness would be positively related to enjoyment and negatively to boredom (cf. Frenzel et al. 2007; Goetz et al. 2006, 2013; see also Lei et al. 2018).

$\mathrm{H} 2 \mathrm{~b}$ : In contrast, conflict was expected to be related to higher boredom and anxiety (cf. Frenzel et al. 2007; Goetz et al. 2013) and lower enjoyment of literacy and mathematics (cf. Goetz et al. 2013).

H2c: No specific hypotheses were set for the role of teacher-student closeness in anxiety because the related previous results have been contradictory (cf. Arbeau et al. 2010; Elmelid et al. 2015; Frenzel et al. 2007; Goetz et al. 2006, 2013; see also Lei et al. 2018).

$\mathrm{H} 2 \mathrm{~d}$ : Due to the lack of previous research, we did not set specific hypotheses regarding the moderating role of temperament.

Adolescents' gender, subject-specific attainment values and academic skills were controlled for in all the analyses to predict academic subject-specific achievement emotions. Gender differences in achievement emotions have been reported (Pekrun et al. 2011; Soric et al. 2013), suggesting that male students have a tendency to report higher levels of negative achievement emotions and lower levels of positive achievement emotions than female students, with the exception of anxiety, in which female students report higher levels than or equal levels to male students. Also, attainment values and skills are assumed to have an impact on achievement emotions through the control-value theory of achievement emotions (Pekrun 2006, 2014). In the present study, these were controlled for in aiming to reveal unique associations between self-concepts of ability, teacher-child relationships and achievement emotions.

\section{Method}

\section{Participants and procedure}

A total of 854 primary school students (464 girls, 390 boys) from two municipalities in central Finland participated in the study. Parental written consent and child assent were required for student participation. The teachers of the participating classrooms also gave their written consent for the data collection to be conducted during their lessons, and the research plan was approved by the local ethics committee. The students came from 57 sixth-grade classes (class size: $M=21, \mathrm{SD}=5.3$ ). The mean age of the participating students at the beginning of the study was 12.29 years $(\mathrm{SD}=0.40)$. The sample was fairly representative of the general Finnish population; however, compared to the same-age Finnish population, the parents in the sample were slightly more educated (Official Statistics of Finland 2016a), single-parent 
households were underrepresented, and two-parent households were overrepresented (Official Statistics of Finland 2016b).

The collection of data on the student participants was conducted during normal school days. The questionnaires were administered by trained test administrators. Temperament evaluations of the adolescents were collected via questionnaires sent to the parents. The data were gathered in autumn 2014.

\section{Measures}

Self-concept of ability The adolescents' self-concepts of ability in maths and literacy were assessed using a scale adapted from Eccles and Wigfield (1995) and Spinath and Steinmayr (2008). The questionnaire included three items for both maths and literacy (e.g. How good are you at maths calculation problems/reading precisely and fast?) assessed on a 5-point Likert scale $(1=$ very poor to $5=$ very good; see also Pesu et al. 2018). The Cronbach's alpha reliability for the self-concept of maths ability was 0.85 , and for the self-concept of literacy ability, it was 0.70 .

Teacher-student relationship The quality of the adolescents' relationship with their classroom teachers was assessed using a short Finnish version of the Student-Teacher Relationship Scale (STRS, short form; Pianta 2001; see also Jerome et al. 2009). The scale was designed to measure adolescents' experience of closeness (five items, e.g. I have a close and warm relationship with my teacher) and conflict (six items, e.g. I often fight with my teacher) with their classroom teacher on a 5-point Likert scale ranging from 1 (I disagree) to 5 (I agree). The Cronbach's alpha for closeness was 0.82 , and for conflict, it was 0.76 .

Achievement emotions Adolescents' enjoyment, boredom and anxiety towards mathematics and literacy were assessed using a Finnish version of the Achievement Emotions Questionnaire (AEQ; Pekrun et al. 2011; for validity of the Finnish version, see Sainio et al. 2020). The questionnaire included three items for enjoyment (e.g. I enjoy acquiring new knowledge) and anxiety (e.g. I get tense and nervous while studying) and two items for boredom (e.g. I get bored while studying), regarding both maths and literacy. The students were asked to rate the degree to which they experience these emotions towards literacy and maths using a 5-point Likert scale ranging from 1 (disagree) to 5 (agree). The Cronbach's alpha reliability for the emotions towards maths ranged from 0.65 to 0.76 , while those towards literacy ranged from 0.63 to 0.76 .

Student temperament The adolescents' temperament was reported by parents using the Finnish version of the Early Adolescent Temperament Questionnaire (Revised; EATQ-R; Capaldi and Rothbart 1992; Ellis and Rothbart 2001; for the validity of the Finnish sample, see Kiuru et al. 2020). The 56 statements of the questionnaire were designed to measure broader dimensions of temperament, namely, effortful control (e.g. It is easy for me to really concentrate on homework problems; I have a hard time finishing things on time (reversed)), negative affectivity (e.g. I get sad more than other people realise; I get irritated when I have to stop doing something that I am enjoying) and surgency/extraversion (e.g. I would not be afraid to try a risky sport, like deep-sea diving; I am shy (reversed)). Mean scores for effortful control $(\alpha=0.80)$, negative affectivity $(\alpha=0.84)$ and surgency/extraversion $(\alpha=0.74)$ were calculated. 
Control variables Gender was coded as $0=$ girl and $1=$ boy. Attainment values in maths and literacy were assessed by two questions (e.g. How important is it for you to be good at reading and reading comprehension/maths calculation problems?) on a 5-point Likert scale ranging from 1 (not important at all) to 5 (very important) and adapted from Eccles et al. (1983). The Cronbach's alpha value for literacy attainment was 0.82 , and for mathematics, it was 0.84 . Literacy skills were assessed using three subtests, of which two subtests (the error-finding test and the word-chain test) were from Dyslexia Screening Methods for Adolescents and Adults by Holopainen et al. (2004; see also Kiuru et al. 2011). The third test was the short version of Salzburg's reading fluency test (Landerl et al. 1997). A summed score of the three subtests was created by calculating the mean of the standardised test scores. The Cronbach's alpha reliability for literacy skills was 0.87 . Mathematics performance was measured using the three-minute basic arithmetic test (Aunola and Räsänen 2007; see also Räsänen et al. 2009). The test-retest reliability for this task was found to be 0.86 (Räsänen et al. 2009).

\section{Analysis strategy}

Structural equation modelling was used to answer the research questions. The analyses were carried out according to the following steps. First, we investigated the descriptive statistics. Second, we built measurement models separately for each construct and school subject in question. Third, we integrated these separate measurement models into the final measurement models. In these measurement models, latent factors were allowed to correlate with each other.

Fourth, structural equation models were constructed separately for each school subject. In these models, latent factors of adolescents' subject-specific emotions (i.e. enjoyment, anxiety and boredom) were predicted by latent factors of subject-specific self-concepts of ability as well as by latent factors of closeness and conflict in the teacher-student relationship. The predictors, namely, the latent factors of the self-concept of ability, closeness in the studentteacher relationship and conflict in the teacher-student relationship, were allowed to correlate. In addition, the residuals of the outcome variables, namely, the latent factors of achievement emotions, were allowed to correlate. We also controlled for the effects of subject-specific attainment values, gender and academic skill level on the particular school subject.

Finally, to investigate the role of temperament characteristics (i.e. effortful control, negative affectivity and surgency/extraversion) in the examined associations, we added the following interaction terms: self-concept of ability $\times$ particular temperament characteristic, and conflict and closeness in student-teacher relationship $\times$ temperament characteristic to the models. The main effects of the temperament characteristics were also included in these models. Follow-up analyses on the significant interaction terms were carried out by calculating and visualising simple slopes separately for adolescents with low ( $-1 \mathrm{SD})$ and high $(+1 \mathrm{SD})$ levels of the particular temperament dimension. We also used the computational tool developed by Preacher et al. (2006) to calculate the statistical significance of these simple slopes.

The statistical analyses were performed using the Mplus statistical package (Version 7.3) and applying the complex approach (Muthén and Muthén 1998-2015). This method estimates the models at the level of the whole sample, but corrects possible distortions of standard errors in the estimation caused by the clustering of observations (classroom differences). The proportion of missing data for the main study variables ranged from 1.5 to $21.4 \%(M=6.51$; $\mathrm{SD}=7.96)$. Little's (1988) MCAR test indicated that data were not missing completely at random: $\chi^{2}(334)=632.61, p<0.001$. Thus, in the analyses, full-information maximum 
likelihood procedures were used to deal with the missing data. Since not all the study variables were normally distributed, we used maximum likelihood robust (MLR) estimation. The MLR estimator produces robust standard errors by means of a sandwich estimator and a $\chi^{2}$ test statistic for non-normal outcomes. Model fit was investigated using the root mean square error of approximation (RMSEA), the comparative fit index (CFI), the Tucker-Lewis index (TLI) and the standardised root mean square residual (SRMR). A model typically fits the data well when the $p$ value associated with the $\chi^{2}$ test is non-significant. RMSEA values below 0.06 and SRMR values below 0.08 indicate a relatively good fit between the hypothesised model and the observed data (see also $\mathrm{Hu}$ and Bentler 1999). Because the $\chi^{2}$ test is sensitive to sample size, the use of relative goodness-of-fit indices is also recommended in the case of large sample sizes (Bentler and Bonett 1980). Consequently, the following two relative goodness-of-fit indices were also used to evaluate model fit: the CFI and the TLI. CFI and TLI values close to 0.95 indicate a relatively good fit to the data (see also $\mathrm{Hu}$ and Bentler 1999).

\section{Results}

\section{Measurement models}

Measurement models were built separately for each school subject using confirmatory factor analysis, which enabled us to take measurement error into account. In these models, latent factors were allowed to correlate. The final measurement models including all latent factors were shown to fit the data well for both school subjects: $\chi^{2}(265)=603.60-641.90, p<0.001$, $\mathrm{RMSEA}=0.04, \mathrm{CFI}=0.94, \mathrm{TLI}=0.93$ and $\mathrm{SRMR}=0.04$. The factor loadings of the latent factors in the final models ranged from 0.43 to 0.88 . The fact that the models fit the data well and that the factor loadings were high suggest good construct validity and item reliability.

\section{Structural equation models}

We next built a separate structural equation model (SEM) for each school subject to predict the adolescents' achievement emotions by using their self-concept of ability and closeness and conflict in the teacher-student relationship. The effects of the adolescents' attainment values, gender and academic skills were controlled for in all the analyses. The final models containing only statistically significant paths fit the data well: for mathematics, $\chi^{2}(272)=645.87, p$ $<0.001, \mathrm{RMSEA}=0.04, \mathrm{CFI}=0.94, \mathrm{TLI}=0.93$ and $\mathrm{SRMR}=0.04$; and for literacy, $\chi^{2}(272)=611.01, p<0.001, \mathrm{RMSEA}=0.04, \mathrm{CFI}=0.94, \mathrm{TLI}=0.93$ and $\mathrm{SRMR}=0.05$. The final model for mathematics is shown in Fig. 1 and that for literacy in Fig. 2.

\section{Self-concept of ability, temperament and achievement emotions}

The descriptive statistics of the study variables are presented in Table 1, and a correlation matrix is shown in Table 2. Our first research question was to investigate the extent to which the adolescents' self-concept of ability is associated with their achievement emotions (i.e. enjoyment, anxiety and boredom) towards literacy and mathematics. The results (see Figs. 1 and 2) showed that after controlling for the effects of attainment values, gender and academic skill level in the particular subject, self-concepts of ability were positively related to the adolescents' enjoyment of both school subjects and negatively related to anxiety experienced 


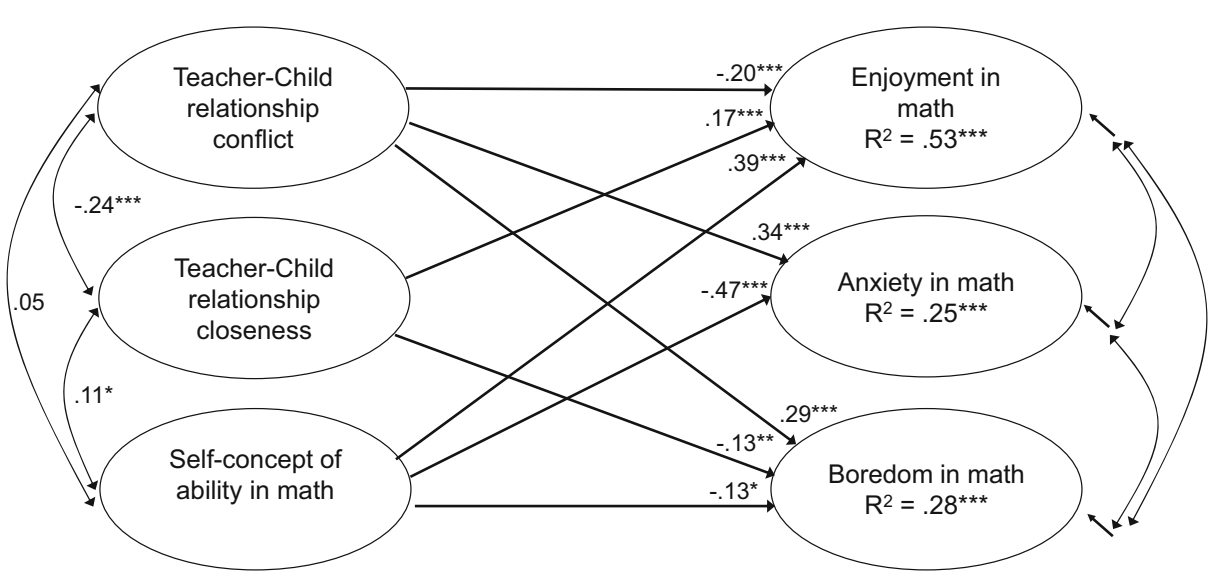

Fig. 1 Associations of teacher-student relationship and self-concept of ability with students' emotions towards mathematics: standardised solution of the structural equation model. The effects of attainment value, gender and math performance level were controlled for in the analysis. ${ }^{*} p<0.05 ; * * p<0.01$; $* * * p<0.001$

towards the school subjects. Furthermore, the self-concept of ability was negatively related to boredom experienced in mathematics but not in literacy (see Fig. 1).

We also investigated the extent to which adolescent temperament moderated the associations of the self-concepts of ability in mathematics and literacy with the adolescents' achievement emotions. This was analysed by adding the interaction terms of self-concept of ability in maths and literacy $\times$ temperament dimension to the previous models (see Fig. 3). Also, the main effects of temperament were included in all the models. The results showed that one out of six of the interaction terms tested was statistically significant: the interaction term of selfconcept of ability in literacy $\times$ effortful control was a significant predictor of the adolescents' anxiety towards literacy $(\beta=0.10, \mathrm{SE}=0.05, p=0.035$; Fig. 3$)$. For adolescents with weaker effortful control, a lower self-concept of ability in literacy was related to more anxiety experienced towards literacy $(\beta=-0.34, \mathrm{SE}=0.06, p<0.001)$. For adolescents with a higher level of effortful control, anxiety did not change as a function of the self-concept of ability

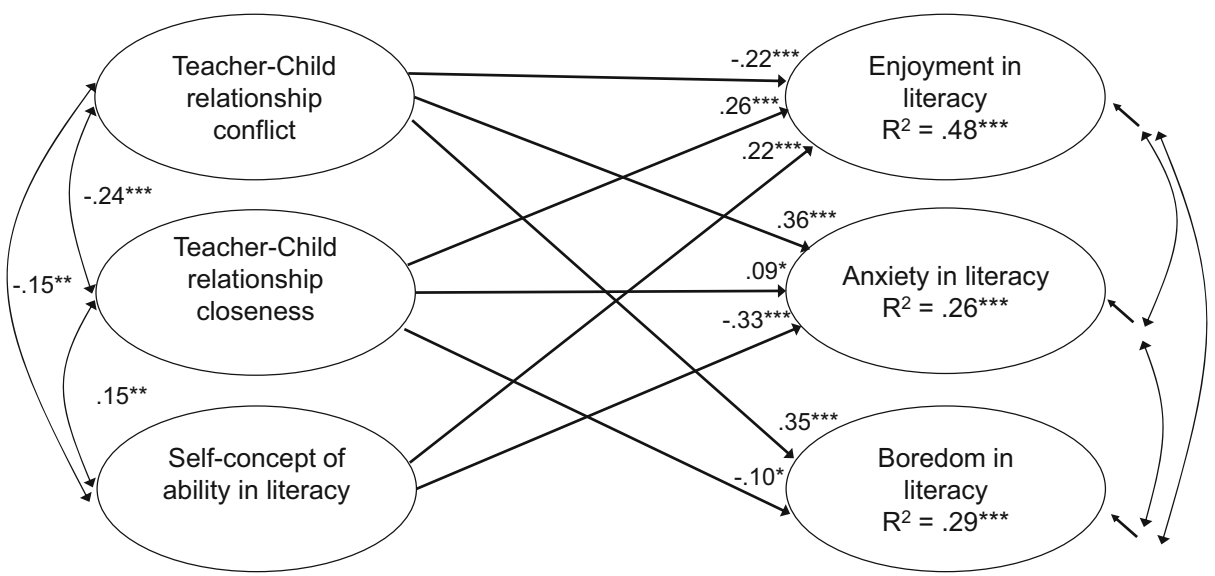

Fig. 2 Associations of teacher-student relationship and self-concept of ability with students' emotions towards literacy: standardised solution of the structural equation model. The effects of attainment value, gender and literacy skill level were controlled for in the analysis. $* p<0.05 ; * * p<0.01 ; * * * p<0.001$ 
Table 1 The descriptive statistics of the main study variables

\begin{tabular}{llll}
\hline Variable & $n$ & $M$ & SD \\
\hline Reading self-concept of ability & 850 & 3.96 & 0.54 \\
Maths self-concept of ability & 850 & 3.84 & 0.73 \\
Closeness with teacher & 845 & 2.32 & 0.83 \\
Conflict with teacher & 847 & 1.63 & 0.67 \\
Enjoyment towards literacy & 849 & 3.12 & 0.85 \\
Anxiety towards literacy & 844 & 1.85 & 0.78 \\
Boredom towards literacy & 841 & 2.11 & 1.02 \\
Enjoyment towards maths & 838 & 3.28 & 0.96 \\
Anxiety towards maths & 842 & 1.85 & 0.81 \\
Boredom towards maths & 841 & 2.01 & 1.02 \\
Negative affectivity & 678 & 2.30 & 0.53 \\
Surgency & 678 & 3.47 & 0.66 \\
Effortful control & 678 & 3.60 & 0.57 \\
\hline
\end{tabular}

$(\beta=-0.14, \mathrm{SE}=0.11, p=0.215)$. The main effect of adolescents' effortful control on literacy anxiety, in turn, was not significant $(\beta=-0.03, \mathrm{SE}=0.03, p=0.207)$. None of the interaction terms between adolescent temperament characteristics and the self-concept of ability in maths had significant effects on math-related achievement emotions.

\section{Quality of teacher-student relationship, temperament and achievement emotions}

Our second research question was formulated to investigate the extent to which closeness and conflict in the teacher-child relationship are associated with adolescents' achievement emotions (i.e. enjoyment, anxiety and boredom) towards literacy and mathematics. The results (see Figs. 1 and 2) showed, after controlling for the effects of attainment values, gender and academic skill level in the particular subject, that conflict with the teacher was negatively related to enjoyment and positively related to anxiety and boredom in both school subjects. Closeness with the teacher, in turn, was positively related to enjoyment and negatively related to boredom in both school subjects. Furthermore, closeness with the teacher was positively related to anxiety, but only in literacy (see Fig. 2).

To examine the moderating role of temperament, the interaction terms of quality of teacherstudent relationship with respect to conflict and closeness $\times$ temperament dimension were next added to the previous models. Furthermore, the main effects of temperament were included in all the models. The results showed that two out of 12 interaction terms tested were statistically significant.

First, the interaction term conflict with teacher $\times$ surgency was statistically significant in predicting the adolescents' feelings of enjoyment towards literacy $(\beta=0.12, \mathrm{SE}=0.05, p=$ 0.013; see Fig. 4). For adolescents with low levels of surgency, lower levels of teacher-student conflict were associated with greater enjoyment of literacy $(\beta=-0.44, \mathrm{SE}=0.06, p<0.001)$, whereas for students with higher levels of surgency, enjoyment did not change as a function of teacher-student conflict $(\beta=-0.20, \mathrm{SE}=0.11, p=0.06)$. In turn, the main effect of the adolescents' surgency on literacy enjoyment was not significant $(\beta=-0.02, \mathrm{SE}=0.03, p=0.537)$.

Second, the results showed that the interaction term closeness with teacher $\times$ effortful control was statistically significant in predicting the adolescents' feelings of anxiety towards literacy $(\beta=-0.11, \mathrm{SE}=0.06, p=0.042$; see Fig. 5). For adolescents with weak effortful control, higher levels of teacher-student closeness were associated with more anxiety towards 


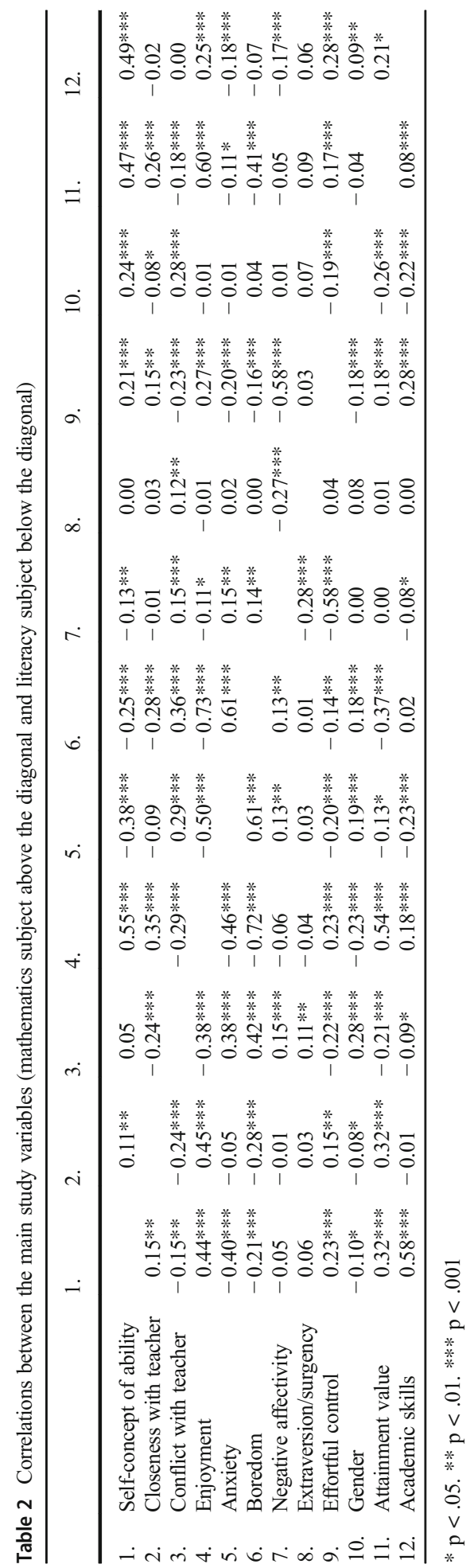




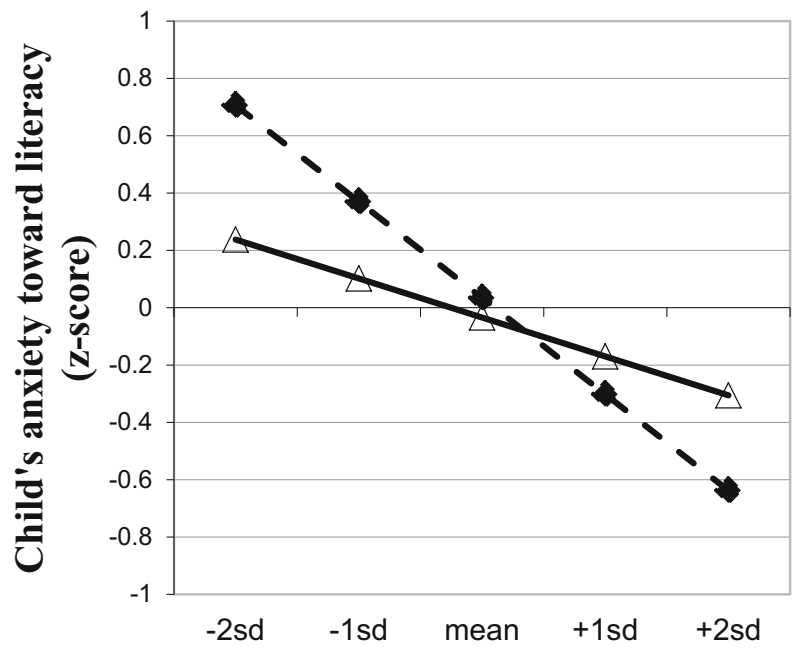

Self-concept of ability

——Effortful control (-1SD)

$\_$Effortful control (+1SD)

Fig. 3 Effortful control as a moderator of the associations between literacy self-concept of ability and anxiety towards literacy learning

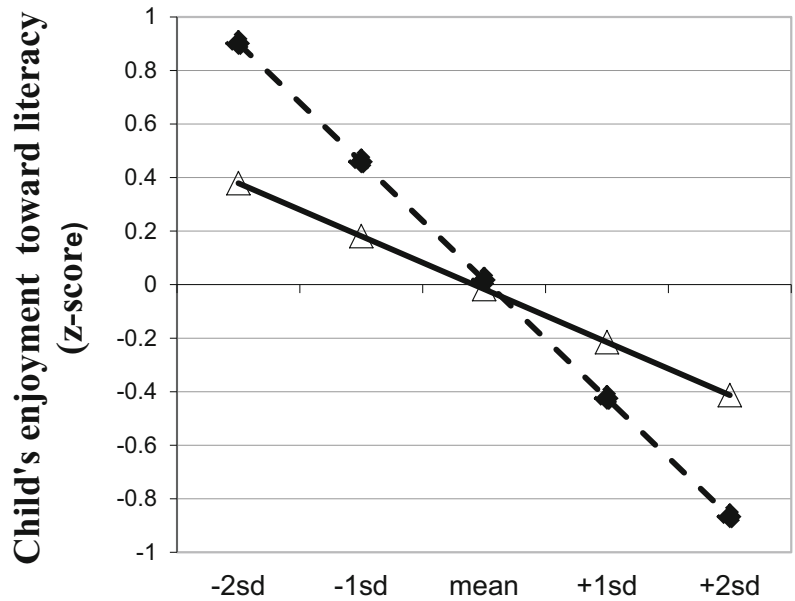

Conflict

$\longrightarrow$ - Surgency $(-1 \mathrm{SD}) \longrightarrow$ Surgency $(+1 \mathrm{SD})$

Fig. 4 Surgency as a moderator of the associations between conflict in teacher-student relationship and enjoyment towards literacy learning 


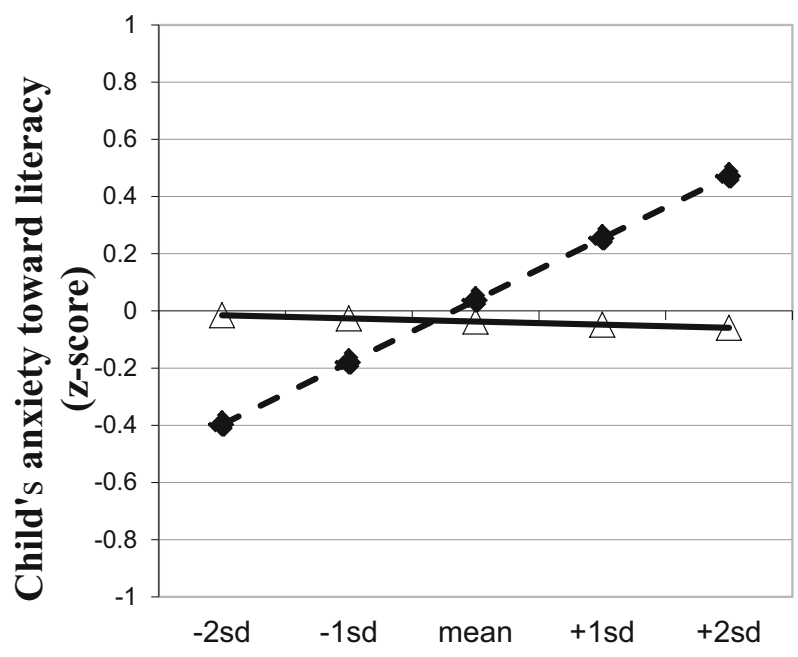

Closeness

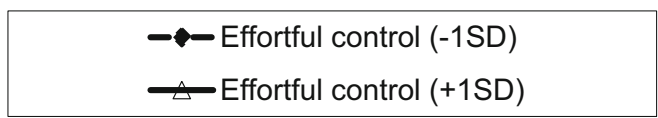

Fig. 5 Effortful control as a moderator of the associations between closeness in teacher-student relationship and anxiety towards literacy learning

literacy learning $(\beta=0.22, \mathrm{SE}=0.09, p=0.02)$. In turn, for adolescents with higher levels of effortful control, anxiety towards literacy learning did not change as a function of teacherstudent closeness $(\beta=-0.01, \mathrm{SE}=0.06, p=0.862)$. The main effect of the adolescents' effortful control on literacy anxiety was not significant $(\beta=-0.04, \mathrm{SE}=0.03, p=0.17)$. None of the interaction terms between adolescent temperament characteristics and student-teacher relationship quality had significant effects on mathematics-related achievement emotions.

\section{Discussion}

The aim of this study was to investigate the associations of the self-concept of ability and the quality of the teacher-student relationship with adolescents' achievement emotions regarding literacy and mathematics and whether adolescent temperament moderates these associations. The results showed, first, that in both school subjects, high self-concepts were related to higher enjoyment and lower anxiety. A high self-concept was also related to a lower level of boredom in mathematics. Second, in both school subjects, a closer and less conflictual relationship with the teacher was related to higher levels of enjoyment and lower levels of boredom, whereas conflict in the teacher-student relationship was related to higher anxiety levels in both school subjects. Third, the associations of the self-concept of ability with achievement emotions were generally stronger in mathematics than in literacy. In mathematics, domain-specific associations were not dependent on student temperament, whereas three significant interaction effects with temperament were observed when predicting achievement emotions towards literacy. 


\section{Self-concepts of ability, temperament and achievement emotions}

Our first aim was to investigate the relations between domain-specific self-concepts of ability and achievement emotions towards literacy and mathematics. Perceived control over learning activity is considered to be one of the main determinants in the control-value theory of achievement emotions (Pekrun 2006), and its role in the emergence of achievement emotions has been corroborated by numerous studies, particularly among high school and university students (for an overview, see Pekrun and Perry 2014). The present study provides a novel understanding of the relations between subject-specific self-concepts of ability and achievement emotions in a younger sample (i.e. sixth-grade adolescents).

The findings for enjoyment and anxiety in mathematics and literacy were in line with our H1a and the control-value theory of achievement emotions (Pekrun and Perry 2014). The results for both academic subjects revealed that primary school adolescents' high self-concepts of ability were related to their higher levels of enjoyment and lower levels of anxiety, after controlling for the effects of gender, teacher-student relationship quality, academic skills and attainment values. Our results are similar to earlier findings among high school students (e.g. Goetz et al. 2010). One possible explanation for the results is that a high self-concept of ability is related to students' adaptive beliefs about their abilities to complete a task and about the likelihood of attaining a desired outcome, resulting in positive emotional experiences. A low self-concept of ability, in turn, is not assumed to coincide with such adaptive beliefs; therefore, a lack of belief in one's abilities may result in negative emotions and, in particular, instigate anxiety if the activity is also considered important (Pekrun and Perry 2014).

The results for boredom also partially supported our H1a and the control-value theory of achievement emotions (Pekrun 2006) by showing that a low self-concept of ability was uniquely related to higher levels of boredom in mathematics. This finding is in line with previous results among high school students (Bieg et al. 2013; Goetz et al. 2010). It is possible that when the achievement situation demands exceed students' ability to cope with the situation, they may start to devalue the subject, leading to boredom experiences (Pekrun 2006) characterised by disengagement from school activities. However, a significant association between the self-concept of ability and boredom was not found for literacy after controlling for the effects of gender, teacher-student relationship quality, academic skills and attainment value. The results suggest that in literacy, the self-concept of ability plays a relatively more important role in enjoyment and anxiety than in boredom. These results are in line with some previous studies (Goetz et al. 2010; see also Goetz et al. 2006) showing that the strength of association between self-concept and boredom may be weaker compared to the equivalent relationships with anxiety and enjoyment and stronger in mathematics compared to in verbal domains (e.g. Goetz et al. 2010).

We further aimed to examine the moderating role of adolescent temperament (i.e. surgency/ extraversion, negative affectivity and effortful control) in the associations of self-concepts of literacy and math ability with achievement emotions. To our knowledge, this study is the first to investigate the joint relations of the self-concept of ability and temperament on achievement emotions. The results for mathematics showed generally stronger associations than in literacy. Also, none of the interaction effects were significant, suggesting that the associations between the self-concept of math ability and achievement emotions were not dependent on adolescents' temperament. In turn, for literacy, overall associations between self-concept and achievement emotions were weaker than in maths, and one significant interaction effect (self-concept of ability $\times$ effortful control) when predicting anxiety towards literacy was detected. For 
adolescents with weak temperamental effortful control, a low self-concept of literacy ability was related to higher levels of anxiety towards literacy learning. In other words, adolescents with low effortful control were particularly vulnerable to the detrimental effects of a low selfconcept of ability on anxiety, while they particularly benefitted from a high self-concept of ability. A similar effect was not observed among adolescents with high levels of effortful control. The result supports the control-value theory of achievement emotions (Pekrun and Perry 2014) by showing that a low self-concept of ability is a risk factor for experiencing anxiety in literacy, whereas a high self-concept of ability can act as a buffering factor. Novel to this finding is that the effect was only pronounced for adolescents who had difficulties in selfregulation. This suggests that for adolescents who have weak effortful control, self-concepts might work as a source of emotion regulation; therefore, such adolescents may particularly benefit from shaping their self-appraisals in a more positive direction.

\section{Teacher-student relationship, temperament and achievement emotions}

Our second aim was to investigate how teacher-student relationship quality is related to adolescents' achievement emotions towards literacy and mathematics. Earlier studies have mainly investigated the characteristics of the classroom learning environment (e.g. instruction quality) and their relationship with students' achievement emotions. Thus far, less has been discovered about the role of teacher-student relationship quality, which can vary from one student to another.

The results for predicting enjoyment and boredom on the basis of the teacher-student relationship quality showed that a high level of closeness with the teacher was related to higher levels of enjoyment and lower levels of boredom in both mathematics and literacy, after controlling for the effects of gender, self-concepts of ability, attainment values and academic skill level in the particular subject. A conflictual relationship with the teacher, in turn, was related to lower levels of enjoyment and higher levels of boredom and anxiety in both school subjects. These results are in line with our $\mathrm{H} 2 \mathrm{a}$ and $\mathrm{H} 2 \mathrm{~b}$, previous studies showing that highquality teaching is related to increased enjoyment and decreased boredom (Frenzel et al. 2007; Goetz et al. 2006, 2013; see also Lei et al. 2018), and a study showing that teacher affective support is related to higher enjoyment (Sakiz 2012). These results are also in accordance with previous studies showing that a lower quality of instruction is related to higher levels of boredom and anxiety (Frenzel et al. 2007; Goetz et al. 2006, 2013) and lower levels of enjoyment (Goetz et al. 2013). It is possible that in a warm and supportive teacher-student relationship, adolescents' basic psychological needs for relatedness are fulfilled and teachers are more sensitive and responsive to adolescents' individual learning-related needs. This may enable adolescents to engage in school tasks with enjoyment and curiosity, which is also likely to support better learning outcomes. In contrast, the need for relatedness is unlikely to be fulfilled in a teacher-student relationship characterised by a high level of conflict. As a result, students are likely to experience less enjoyment and more anxiety and boredom towards learning (Skinner et al. 2014).

However, whereas conflict in the teacher-student relationship was found to predict higher levels of anxiety, closeness in the teacher-student relationship was related to higher anxiety in literacy but was not significantly related to anxiety in mathematics. No specific hypotheses were set for the role of teacher-student closeness in anxiety because the previous related results have been contradictory (cf. Arbeau et al. 2010; Elmelid et al. 2015; Frenzel et al. 2007; Goetz et al. 2006, 2013; see also Lei et al. 2018). These results do not support previous ones 
showing that closeness with the teacher, higher quality teaching or teacher support is related to less anxiety (e.g. Arbeau et al. 2010; Frenzel et al. 2007; see also Lei et al. 2018). However, these results are in line with some previous studies that have found that positive instructional practices do not necessarily reduce students' anxiety towards learning (see Becker et al. 2014; Goetz et al. 2013; see also Elmelid et al. 2015). It is possible that anxiety is reduced by increasing control and increased by enhancing the value of the topic (Pekrun 2006). Therefore, a close relationship may convey higher value than control to students, thus increasing anxiety or both high control and value and, thus, leading to non-significant relations between closeness and anxiety (see also Goetz et al. 2013). Overall, the results indicate that students' anxiety levels were more strongly influenced by conflict than closeness in the teacher-student relationship, supporting previous research that has shown that negative interactions with teachers may matter more than positive interactions regarding student outcomes (e.g. Jellesma et al. 2015).

Finally, our aim was also to investigate the extent to which adolescent temperament moderates the associations between the quality of the teacher-student relationship and achievement emotions in mathematics and literacy. As far as we know, our study is the first to investigate the joint relations of the teacher-student relationship quality and temperament on achievement emotions. The results for mathematics showed, first, that none of the interaction effects were significant, suggesting that the associations between the quality of the teacherstudent relationship and achievement emotions were not dependent on adolescents' temperament. In turn, for literacy, two significant interaction effects were found.

First, the interaction effect conflict in teacher-student relationship $\times$ surgency was statistically significant for predicting enjoyment towards literacy. A high level of conflict in the teacher-student relationship was particularly detrimental for literacy enjoyment among adolescents with low surgency (characterised by shyness and low sensation-seeking). In contrast, a low level of conflict in the teacher-student relationship seemed to protect adolescents with low surgency against diminished feelings of enjoyment towards literacy. For adolescents with high surgency (characterised by low shyness and high sensation-seeking), conflict in the teacherstudent relationship was unrelated to enjoyment towards literacy. One explanation for the finding that adolescents with low levels of surgency enjoyed literacy learning more when there was a low level of conflict in the teacher-student relationship is their temperamental tendency to become overstimulated more easily than adolescents with higher surgency (e.g. Rothbart and Hwang 2005). Therefore, they may prefer low-intensity activities and environments, and they may also be more sensitive to the detrimental effects of conflict than less shy people, thus allowing more enjoyment of the school subject when the relationship with the teacher is less conflictual. This result is in line with the goodness-of-fit model (Thomas and Chess 1977) as it shows that classroom factors are related to achievement emotions not solely in isolation but also in conjunction with temperament. In other words, achievement emotions experienced might depend on the extent of fit between temperament and the demands and expectations of the classroom environment. The results are also in line with the findings for other student outcomes in other age groups. For example, Essex et al. (2011) showed that teacher-child relationship conflict in the first grade was related to heightened levels of mental health problems by the seventh grade, particularly among inhibited children (see also diathesis stress and differential susceptibility models; Belsky and Pluess 2009). Shy and inhibited students have been found to have more difficulties in engaging in peer relationships (for a review, see Coplan and Bullock 2012), to like school less (Valiente et al. 2012) and to have more internalised symptoms (for a review, see Klein et al. 2012). Thus, shyness may be a 
vulnerability factor for social and emotional problems, and problems in the teacher-student relationship may pose the additional risk of diminishing their enjoyment of learning for these students (see also Belsky and Pluess 2009).

Second, our results showed that the interaction effect closeness in teacher-student relationship $\times$ effortful control was statistically significant for predicting anxiety towards literacy. Among adolescents with weak effortful control, a very close relationship with the teacher was related to higher levels of anxiety towards literacy. A similar effect was not found for adolescents with a high level of effortful control. These findings differ from those of some previous studies on other student outcomes, such as problem behaviours (Wang et al. 2013) and academic achievement (Rudasill et al. 2010), which have shown that children and adolescents with low levels of effortful control may particularly benefit from a positive teacher-student relationship. However, none of the previous studies have examined anxiety towards academic subjects as an outcome variable. Our finding, indicating that a high level of closeness with the teacher elevated anxiety towards literacy among adolescents with low levels of effortful control, somewhat resembles one prior study among preschoolers that showed that higher instructional support was related to more conflict with the teacher among pupils with lower effortful control (Rudasill et al. 2016; see also Domínguez et al. 2011). Hence, one possible explanation for our finding is that a close relationship with the teacher may highlight the value of the topic for the student (see Pekrun 2006). Due to this, adolescents with weaker effortful control typically characterised by facing challenges in regulating their behaviour and emotions, in particular, might have exhibited elevated anxiety when they had a close relationship with their teacher.

\section{Differences between the literacy and mathematics domains}

Overall, the results of the present study showed that self-concepts of ability and the teacherstudent relationship play a role in students' achievement emotions and that students' temperament, to some extent, moderates these relationships. Interestingly, the pattern of results was slightly different for mathematics and literacy: First, in mathematics, the self-concept of ability was negatively related to boredom, whereas, in literacy, no significant relationship was found. It has been suggested that a stronger relationship in mathematics between self-concept and emotions might reflect the fact that mathematics is more narrowly defined, and thus, have a narrower range of classroom activities compared to those in literacy, therefore restricting the sources of emotions and self-concepts (Goetz et al. 2010). Second, in mathematics, teacher closeness was not significantly related to student anxiety, whereas, in literacy, teacher closeness was related to slightly heightened anxiety. However, this result may at least partially be explained by the interaction effect found in literacy concerning teacher closeness and anxiety.

In mathematics associations between self-concept of ability, teacher-child relationship quality and achievement emotions were not dependent on temperament. Previous research has shown that, in maths development, individual differences increase over time, thus showing a cumulative developmental pattern (Aunola et al. 2004). Reading development typically shows the opposite pattern, particularly in later grade levels; that is, individual differences decrease rather than increase over time showing a compensatory trajectory (e.g. Leppänen et al. 2004; see also Parrila et al. 2005). Thus, one possible explanation for these results in mathematics is that whereas individual differences in maths are wider than in reading, there may be more room in maths for stronger influences of motivational and environmental factors that apply to all adolescents regardless of their temperament. 
In turn, three of the literacy-related associations were moderated by adolescent temperament (i.e. the associations were not true for all the adolescents but depended on adolescent temperament). More specifically, adolescents with low effortful control were particularly vulnerable to the detrimental effects of a low self-concept of ability on anxiety towards literacy, whereas the self-concept of ability was not related to anxiety for adolescents with high effortful control. In other words, a simultaneous low self-concept and low temperamental effortful control posed a double risk for the development of literacy-related anxiety (see also Belsky and Pluess 2009). Also, for adolescents with low effortful control, a close relationship with the teacher was related to higher levels of anxiety towards literacy, whereas closeness in the teacher-student relationship was not related to anxiety for adolescents with high effortful control. Finally, a high level of conflict in the teacher-student relationship was particularly detrimental for literacy enjoyment among adolescents with low surgency (high shyness and low sensation-seeking), whereas conflict in the teacher-student relationship was not related to lower enjoyment among students with high surgency (low shyness and high sensationseeking). One other possible explanation for these moderation effects, seen only in literacy, also relates to the differing contexts of teaching and learning between maths and literacy (see also Vitiello et al. 2012). Compared to mathematics, literacy is typically seen by teachers as less defined, less sequential and more dynamic, and these features have been shown to have consequences on teachers' curricular practices (Stodolsky and Grossman 1995). However, further studies are needed to explore these differences in more detail.

\section{Limitations and future directions}

The present study also has its limitations. First, despite the inclusion of a meaningful set of control variables, this study was correlational in nature; thus, any conclusions on the causal relations between the study constructs cannot be made. Future studies should investigate longitudinal associations between both distal and individual antecedents of achievement emotions and their reciprocal linkages, as suggested by the control-value theory of achievement emotions (see Pekrun and Perry 2014). A longitudinal research design would also allow the testing of mediating mechanisms, between the teacher-student relationship quality, the self-concept of ability and achievement emotions, and how these are further related to academic outcomes.

Second, our sample consisted of 12-year-olds, thus warranting studies with different age groups. Third, it is possible that adolescents' self-reports of emotions, self-concepts and the teacher-child relationship quality may have led to the overestimation of the strengths of the main effects because of the shared method variance. Future studies could, for example, link the self-assessment of emotions to physiological indicators of emotions.

\section{Conclusions and practical implications}

This study extends the work of previous studies on the antecedents of achievement emotions by illustrating the importance of both individual and distal factors in the emergence of achievement emotions. More specifically, our findings suggest that in addition to selfconcepts of ability, the teacher-student relationship quality plays an important role in adolescents' achievement emotions in mathematics and literacy. Moreover, our findings indicate that some of the relations (especially in the literacy domain) between the teacher-student relationship quality, the self-concept of ability and emotions were dependent on student temperament. 
Generally, our results suggest that a higher self-concept of ability is important in promoting positive emotions and lessening negative emotions. Moreover, our study extended previous knowledge by revealing that in literacy, a low self-concept seemed to increase anxiety towards learning for adolescents low in effortful control, whereas a higher self-concept protected against anxiety. Overall, our results suggest that in order to boost students' positive emotions and mitigate their negative emotions towards school, students' self-concepts of ability should be enhanced. In addition, students with low levels of effortful control may particularly benefit from support of their self-concept of ability.

This study contributed to the previous research on teacher-student relationships by demonstrating that teacher-student relationship quality is related to students' emotions and that certain relationship characteristics may be particularly detrimental to students with certain temperament characteristics in terms of achievement emotions towards literacy. Overall, the results suggest that a positive relationship with the teacher may be beneficial for students' achievement emotions. This information is important for educators because teachers' awareness of the associations of the quality of teacher-student relationships with students' achievement emotions may improve the quality of these relationships. A positive relationship with adolescents has the potential to inform teachers about students' needs and, in turn, to enable adolescents to cope constructively with tasks, thus further enhancing their motivation and engagement (Skinner et al. 2014). The results also suggest that a knowledge of students' temperament may provide teachers with further information on how to best meet the students' needs and support their learning and motivation.

Acknowledgements Open access funding provided by University of Jyväskylä (JYU). We would like to express our gratitude to all the adolescents and parents participating in the study and the local school authorities.

Funding information The study was funded by grants from the Academy of Finland (\#266851, 294970).

Open Access This article is licensed under a Creative Commons Attribution 4.0 International License, which permits use, sharing, adaptation, distribution and reproduction in any medium or format, as long as you give appropriate credit to the original author(s) and the source, provide a link to the Creative Commons licence, and indicate if changes were made. The images or other third party material in this article are included in the article's Creative Commons licence, unless indicated otherwise in a credit line to the material. If material is not included in the article's Creative Commons licence and your intended use is not permitted by statutory regulation or exceeds the permitted use, you will need to obtain permission directly from the copyright holder. To view a copy of this licence, visit http://creativecommons.org/licenses/by/4.0/.

\section{References}

Arbeau, K., Coplan, R., \& Weeks, M. (2010). Shyness, teacher-child relationships, and socio-emotional adjustment in grade 1. International Journal of Behavioral Development, 34(3), 259-269.

Aunola, K., \& Räsänen, P. (2007). The 3-minutes Basic Arithmetic Test. Jyväskylä, Finland: Unpublished test material.

Aunola, K., Leskinen, E., Lerkkanen, M.-K., \& Nurmi, J.-E. (2004). Developmental dynamics of math performance from preschool to grade 2. Journal of Educational Psychology, 96, 699-713.

Becker, E. S., Goetz, T., Morger, V., \& Ranellucci, J. (2014). The importance of teachers' emotions and instructional behavior for their students' emotions - an experience sampling analysis. Teaching and Teacher Education, 43, 15-26.

Belsky, J., \& Pluess, M. (2009). Beyond diathesis stress: differential susceptibility to environmental influences. Psychological Bulletin, 135(6), 885-908.

Bentler, P. M., \& Bonett, D. G. (1980). Significance tests and goodness of fit in the analysis of covariance structures. Psychological Bulletin, 88, 588-606. 
Bergin, B., \& Bergin, D. (2009). Attachment in classroom. Educational Psychology Review, 21, 141-170.

Bieg, M., Goetz, T., \& Hubbard, K. (2013). Can I master it and does it matter? An intraindividual analysis on control-value antecedents of trait and state academic emotions. Learning and Individual Differences, 28, 102-108.

Capaldi, D. M., \& Rothbart, M. K. (1992). Development and validation of an early adolescent temperament measure. Journal of Early Adolescence, 12, 153-173.

Coplan, R., \& Bullock, A. (2012). Temperament and peer relationships. In M. Zentner \& R. L. Shiner (Eds.), Handbook of temperament (pp. 442-462). New York: Guilford.

Derryberry, D., \& Rothbart, M. (1997). Reactive and effortful processes in the organization of temperament. Development and Psychopathology, 9(4), 633-652.

Domínguez, X., Vitiello, V., Fuccillo, J., Greenfield, D., \& Bulotsky-Shearer, R. (2011). The role of context in preschool learning: a multilevel examination of the contribution of context-specific problem behaviors and classroom process quality to low-income children's approaches to learning. Journal of School Psychology, 49(2), 175-195.

Eccles, J. S., \& Wigfield, A. (1995). In the mind of the actor: the structure of adolescents' achievement task values and expectancy-related beliefs. Personality and Social Psychology Bulletin, 21(3), 215-225.

Eccles, J., Adler, T. F., Futterman, R., Goff, S. B., Kaczala, C. M., Meece, J. L., et al. (1983). Expectancies, values, and academic behaviors. In J. T. Spence (Ed.), Achievement and achievement motivation (pp. 75146). San Francisco, CA: W.H. Freeman.

Ellis, L.K., \& Rothbart, M.K. (2001). Revision of the early adolescent temperament questionnaire. Poster presented at the 2001 Biennial meeting of the Society for Research in Child Development, Minneapolis, MN. Retrieved from https://research.bowdoin.edu/rothbart-temperament-questionnaires/files/2016/09/lesaellis-srcd-poster-reprint.pdf. Accessed 28 Apr 2015

Elmelid, A., Stickley, A., Lindblad, F., Schwab-Stone, M., Henrich, C., \& Ruchkin, V. (2015). Depressive symptoms, anxiety and academic motivation in youth: do schools and families make a difference? Journal of Adolescence, 45, 174-182.

Essex, M. J., Armstrong, J. M., Burk, L. R., Goldsmith, H. H., \& Boyce, W. T. (2011). Biological sensitivity to context moderates the effects of the early teacher-child relationship on the development of mental health by adolescence. Development and Psychopathology, 23(1), 149-161.

Frenzel, A., Pekrun, R., \& Goetz, T. (2007). Perceived learning environment and students' emotional experiences: a multilevel analysis of mathematics classrooms. Learning and Instruction, 17(5), 478-493.

Goetz, T., \& Hall, N. C. (2014). Academic boredom. In R. Pekrun \& L. Linnenbrink-Garcia (Eds.), International handbook of emotions in education (pp. 311-330). New York: Routledge.

Goetz, T., Pekrun, R., Hall, N., \& Haag, L. (2006). Academic emotions from a social-cognitive perspective: antecedents and domain specificity of students' affect in the context of Latin instruction. British Journal of Educational Psychology, 76(2), 289-308.

Goetz, T., Frenzel, A. C., Hall, N. C., Pekrun, R., \& Lüdtke, O. (2007). Between- and within-domain relations of students' academic emotions. Journal of Educational Psychology, 99(4), 715-733.

Goetz, T., Cronjaeger, H., Frenzel, A. C., Lüdtke, O., \& Hall, N. (2010). Academic self-concept and emotion relations: domain specificity and age effects. Contemporary Educational Psychology, 35(1), 44-58.

Goetz, T., Lüdtke, O., Nett, U. E., Keller, M. M., \& Lipnevich, A. A. (2013). Characteristics of teaching and students' emotions in the classroom: investigating differences across domains. Contemporary Educational Psychology, 38(4), 383-394.

Hamre, B. K., \& Pianta, R. C. (2001). Early teacher-child relationships and the trajectory of children's school outcomes through eighth grade. Child Development, 72(2), 625-638.

Holopainen, L., Kairaluoma, L., Nevala, J., Ahonen, T., \& Aro, M. (2004). Lukivaikeuksien seulontatesti nuorille ja aikuisille [Dyslexia screening test for youth and adults]. Jyväskylä, Finland: Jyväskylän yliopistopaino [University of Jyväskylä].

Hu, L., \& Bentler, P. M. (1999). Cutoff criteria for fit indexes in covariance structure analysis: conventional criteria versus new alternatives. Structural Equation Modeling, 6, 1-55.

Jellesma, F. C., Zee, M., \& Koomen, H. M. Y. (2015). Children's perceptions of the relationship with the teacher: associations with appraisals and internalizing problems in middle childhood. Journal of Applied Developmental Psychology, 36, 30-38.

Jerome, E. M., Hamre, B. K., \& Pianta, R. C. (2009). Teacher-child relationship from kindergarten to sixth grade: early childhood predictors of teacher-perceived conflict and closeness. Social Development, 18(4), 915-945.

Kiuru, N., Haverinen, K., Salmela-Aro, K., Nurmi, J-E., Savolainen, H., \& Holopainen, L. (2011). Students with reading and spelling disabilities: peer groups and educational attainment in secondary education. Journal of Learning Disabilities, 44, 556-569. 
Kiuru, N., Hirvonen, R., \& Ahonen, T. (2020). Assessing temperament among Finnish early adolescents and their parents: psychometric properties of the short forms of the temperament questionnaires. Merrill-Palmer Quarterly (in press)

Klein, D. N., Dyson, M. W., Kujawa, A. J., \& Kotov, R. (2012). Temperament and internalizing disorders. In M. Zentner \& R. L. Shiner (Eds.), Handbook of temperament (pp. 541-561). New York: Guilford.

LaBillois, J. M., \& Lagacé-Séguin, D. G. (2009). Does a good fit matter? Exploring teaching styles, emotion regulation, and child anxiety in the classroom. Early Child Development, 179(3), 303-315.

Landerl, K., Wimmer, H., \& Moser, E. (1997). Salzburger Lese and Rechtschreibtest [Salzburg's reading and spelling test]. Bern, Switzerland: Hans Huber.

Lei, H., Cui, Y., \& Chiu, M. (2018). The relationship between teacher support and students' academic emotions: a meta-analysis. Frontiers in Psychology, 8, 1-12.

Leppänen, U., Niemi, P., Aunola, K., \& Nurmi, J.-E. (2004). Development of reading skills among preschool and primary school pupils. Reading Research Quarterly, 39(1), 72-93.

Little, R. J. A. (1988). A test of missing completely at random for multivariate data with missing values. Journal of the American Statistical Association, 83(404), 1198-1202.

Lonigan, C. J., Vasey, M. W., Phillips, B. M., \& Hazen, R. A. (2004). Temperament, anxiety, and the processing of threat-relevant stimuli. Journal of Child and Adolescent Psychology, 33(1), 8-20.

Meyer, D. (2014). Situating emotions in classroom practices. In R. Pekrun \& L. Linnenbrink-Garcia (Eds.), International handbook of emotions in education (pp. 458-472). New York: Routledge.

Muthén, L. K., \& Muthén, B. O. (1998-2015). Mplus user's guide (7th ed.). Los Angeles: Muthén \& Muthén Retrieved from http://www.statmodel.com/download/usersguide/MplusUserGuideVer_7.pdf.

Official Statistics of Finland. (2016a). Educational structure of population (e-publication). Helsinki, Finland: Statistics Finland Retrieved from www.stat.fi/til/vkour/2014/vkour_2014_2015-11-05_tie_001_en.html.

Official Statistics of Finland. (2016b). Families. In Appendix Table 3: families with underage children by type in 1950-2014 (e-publication). Helsinki, Finland: Statistics Finland Retrieved from www.stat.fi/til/perh/2014 /perh_2014_2015-05-28_tau_003_en.html.

Pakarinen, E., Silinskas, G., Hamre, B. K., Metsäpelto, R.-L., Lerkkanen, M.-K., Poikkeus, A.-M., \& Nurmi, J.E. (2018). Cross-lagged associations between problem behaviors and teacher-student relationships in early adolescence. Journal of Early Adolescence, 38(8), 1100-1141. https://doi.org/10.1177/0272431617714328.

Parrila, R., Aunola, K., Leskinen, E., Nurmi, J.-E., \& Kirby, J. R. (2005). Development of individual differences in reading: results from two longitudinal studies. Journal of Educational Psychology, 97(3), 299-319.

Pekrun, R. (2006). The control-value theory of achievement emotions: assumptions, corollaries, and implications for educational research and practice. Educational Psychology Review, 18(4), 315-341.

Pekrun, R., \& Perry, R. P. (2014). Control-value theory of achievement emotions. In R. Pekrun \& L. Linnenbrink-Garcia (Eds.), International handbook of emotions in education (pp. 120-141). New York: Routledge.

Pekrun, R., Goetz, T., Titz, W., \& Perry, R. P. (2002). Academic emotions in students' self-regulated learning and achievement: a program of qualitative and quantitative research. Educational Psychologist, 37(2), 91-105.

Pekrun, R., Goetz, T., Frenzel, A. C., Barchfeld, P., \& Perry, R. P. (2011). Measuring emotions in students' learning and performance: the Achievement Emotions Questionnaire. Contemporary Educational Psychology, 36(1), 36-48.

Pesu, L., Aunola, K., Viljaranta, J., Hirvonen, R., \& Kiuru, N. (2018). The role of mothers' beliefs in students' self-concepts of abilities during the transition to lower secondary school. Learning and Individual Differences, 65, 230-240.

Pianta, R. C. (2001). The student-teacher relationship scale. Odessa, FL: Personality Assessment Research.

Preacher, K. J., Curran, P. J., \& Bauer, D. J. (2006). Computational tools for probing interaction effects in multiple linear regression, multilevel modeling, and latent curve analysis. Journal of Educational and Behavioral Statistics, 31(4), 437-448.

Raccanello, D., Brondini, M., \& De Bernardi, B. (2013). Achievement emotions in elementary, middle, and high school: how do students feel about specific contexts in terms of settings and subject-domains? Scandinavian Journal of Psychology, 54(6), 477-484.

Räsänen, P., Salminen, J., Wilson, A. J., Aunio, P., \& Dehaene, S. (2009). Computer-assisted intervention for children with low numeracy skills. Cognitive Development, 24(4), 450-472.

Roorda, D., Koomen, H., Spilt, J., \& Oort, F. (2011). The influence of affective teacher-student relationships on students' school engagement and achievement: a meta-analytic approach. Review of Educational Research, 81(4), 493-529.

Rothbart, M. K. (2011). Becoming who we are. Temperament and personality in development. New York: Guilford. 
Rothbart, M. K., \& Bates, J. E. (2006). Temperament. In W. Damon, R. M. Lerner, \& N. Eisenberg (Eds.), Handbook of child psychology: volume 3, social, emotional, and personality development (pp. 105-176). New York: Wiley.

Rothbart, M. K., \& Derryberry, D. (1981). Development of individual differences in temperament. In M. E. Lamb \& A. L. Brown (Eds.), Advances in developmental psychology, Vol 1. New Jersey: Lawrence Erlbaum.

Rothbart, M., \& Hwang, J. (2005). Temperament and the development of competence and motivation. In A. J. Elliot \& C. S. Dweck (Eds.), Handbook of competence and motivation (pp. 167-184). New York: Guilford.

Rothbart, M. K., \& Jones, L. B. (1998). Temperament, self-regulation, and education. School Psychology Review, 27(4), 4479-4491.

Rudasill, K. M., Gallagher, K. C., \& White, J. M. (2010). Temperamental attention and activity, classroom emotional support, and academic achievement in third grade. Journal of School Psychology, 48(2), 113-134.

Rudasill, K. M., Hawley, L., Molfese, V. J., Tu, X., Prokasky, A., \& Sirota, K. (2016). Temperament and teacherchild conflict in preschool: the moderating roles of classroom instructional and emotional support. Early Education and Development, 27(7), 859-874.

Sainio, P., Eklund, K., Hirvonen, R., Ahonen, T., \& Kiuru, N. (2020). Adolescents' academic emotions and academic achievement across the transition to lower secondary school: The role of learning difficulties. Scandinavian Journal of Educational Research. https://doi.org/10.1080/00313831.2019.1705900.

Sakiz, G. (2012). Perceived instructor affective support in relation to academic emotions and motivation in college. Educational Psychology, 32(1), 63-79.

Sakiz, G., Pape, S., \& Woolfolk Hoy, A. (2012). Does perceived teacher affective support matter for middle school student in mathematics classrooms? Journal of School Psychology, 50(2), 235-255.

Shiner, R. L., \& Caspi, A. (2012). Temperament and the development of personality traits. In M. Zentner \& R. L. Shiner (Eds.), Handbook of temperament (pp. 497-518). New York: Guilford.

Shiner, R. L., Buss, K. A., McClowry, S. G., Putnam, S. P., Saudino, K. J., \& Zentner, M. (2012). What is temperament now? Assessing progress in temperament research on the twenty-fifth anniversary of Goldsmith et al. (1987). Child Development Perspectives, 6(4), 436-444.

Skinner, E., Pitzer, J., \& Brule, H. (2014). The role of emotion in engagement, coping, and the development of motivational resilience. In R. Pekrun \& L. Linnenbrink-Garcia (Eds.), International handbook of emotions in education (pp. 331-347). New York: Routledge.

Soric, I., Penezic, Z., \& Buric, I. (2013). Big Five personality traits, cognitive appraisals and emotion regulation strategies as predictors of achievement emotions. Psychological Topics, 22, 325-349.

Spinath, B., \& Steinmayr, R. (2008). Longitudinal analysis of intrinsic motivation and competence beliefs: is there a relation over time? Child Development, 79(5), 1555-1569.

Stodolsky, S., \& Grossman, P. (1995). The impact of subject matter on curricular activity: an analysis of five academic subjects. American Educational Research Journal, 32(2), 227-249.

Thomas, A., \& Chess, S. (1977). Temperament and development. Oxford, England: Brunner/Mazel.

Valiente, C., Swanson, J., \& Lemery-Chalfant, K. (2012). Kindergartners' temperament, classroom engagement, and student-teacher relationship: moderation by effortful control. Social Development, 21(3), 558-576.

Verschueren, K. (2015). Middle childhood teacher-child relationships: insights from an attachment perspective and remaining challenges. New directions for child and adolescent development, 148, 77-91.

Vitiello, V., Moas, O., Henderson, H., Greenfield, D., \& Munis, P. (2012). Goodness of fit between children and classrooms: Effects of child temperament and preschool classroom quality on achievement trajectories. Early Education \& Development, 23, 302-322.

Wang, M.-T., Brinkworth, M., \& Eccles, J. (2013). Moderating effects of teacher-student relationship in adolescent trajectories of emotional and behavioral adjustment. Developmental Psychology, 49(4), 69.

Publisher's note Springer Nature remains neutral with regard to jurisdictional claims in published maps and institutional affiliations. 
Anna-Leena Clem. Department of Psychology, University of Jyväskylä, P.O. Box 35, 40014 Jyväskylä, Finland

Current themes of research:

Antecedents of adolescents' self-concepts of ability and achievement emotions in the school context.

Most relevant publications in the field of Psychology of Education:

Clem, A-L., Aunola, K., Hirvonen, R., Määttä, S., \& Nurmi, J.-E., \& Kiuru, N. (2018). Adolescents' domain-specific self-concepts of ability predict their domain-specific causal attributions: a longitudinal study. Merrill-Palmer Quarterly, 64, 530-569.

Kathleen M. Rudasill. Department of Foundations of Education, Virginia Commonwealth University, Richmond, VA, USA

Current themes of research:

Temperamental characteristics. Academic and social success. Classroom processes. Studentteacher interactions.

Most relevant publications in the field of Psychology of Education:

https://scholar.google.fi/citations?user=XINRk9kAAAAJ\&hl=fi\&oi=ao

Riikka Hirvonen. Department of Psychology, University of Jyväskylä, P.O. Box 35, 40014 Jyväskylä, Finland

Current themes of research:

Children's and adolescents' well-being. Motivation. Learning-related emotions and behavior. Most relevant publications in the field of Psychology of Education:

ORCID: 0000-0001-5348-4801

Kaisa Aunola. Department of Psychology, University of Jyväskylä, P.O. Box 35, 40014 Jyväskylä, Finland

\section{Current themes of research:}

Parenting and family relations. Family as developmental context for children's socio-emotional and academic learning. Quantitative methods related on modeling developmental dynamics.

Most relevant publications in the field of Psychology of Education:

ORCID: 0000-0001-8866-6736 
Noona Kiuru. Department of Psychology, University of Jyväskylä, P.O. Box 35, 40014 Jyväskylä, Finland. E-mail: noona.h.kiuru@jyu.fi

Current themes of research:

Individual and environment-related risk and protective factors underlying children's and adolescents' learning. Well-being and successful educational transitions.

Most relevant publications in the field of Psychology of Education:

ORCID: 0000-0002-2334-8507 